\title{
Article \\ Enhanced Energy Density for P-Doped Hierarchically Porous Carbon-Based Symmetric Supercapacitor with High Operation Potential in Aqueous $\mathrm{H}_{2} \mathrm{SO}_{4}$ Electrolyte
}

\author{
Xiaozhong Wu ${ }^{1}{ }^{\oplus}$, Xinping Yang ${ }^{1}$, Wei Feng ${ }^{2}$, Xin Wang ${ }^{1}$, Zhichao Miao ${ }^{1} \mathbb{C}$, Pengfei Zhou ${ }^{1}$, Jinping Zhao ${ }^{1}$, \\ Jin Zhou ${ }^{1}$ (D) and Shuping Zhuo ${ }^{1, *(D)}$ \\ 1 School of Chemistry and Chemical Engineering, Shandong University of Technology, Zibo 255049, China; \\ xiaozhongwu@yeah.net (X.W.); xinpingyang996@163.com (X.Y.); wang0126xin@163.com (X.W.); \\ miaozhichao@sdut.edu.cn (Z.M.); pengfeizhou1231@126.com (P.Z.); jpzhao@sdut.edu.cn (J.Z.); \\ zhoujin@sdut.edu.cn (J.Z.) \\ 2 Shandong Qilu Keli Chemical Institute Co., Ltd., Zibo 255086, China; Fengwei007@126.com \\ * Correspondence: zhuosp_academic@yahoo.com
}

Citation: Wu, X.; Yang, X.; Feng, W.; Wang, X.; Miao, Z.; Zhou, P.; Zhao, J.; Zhou, J.; Zhuo, S. Enhanced Energy Density for P-Doped Hierarchically Porous Carbon-Based Symmetric Supercapacitor with High Operation Potential in Aqueous $\mathrm{H}_{2} \mathrm{SO}_{4}$ Electrolyte. Nanomaterials 2021, 11, 2838. https://doi.org/10.3390/ nano11112838

Academic Editors: Jung-Sang Cho and Jung-Woo Lee

Received: 4 September 2021 Accepted: 20 October 2021 Published: 25 October 2021

Publisher's Note: MDPI stays neutral with regard to jurisdictional claims in published maps and institutional affiliations.

Copyright: (c) 2021 by the authors. Licensee MDPI, Basel, Switzerland. This article is an open access article distributed under the terms and conditions of the Creative Commons Attribution (CC BY) license (https:/ / creativecommons.org/licenses/by/ $4.0 /)$.

\begin{abstract}
Phosphorus-doped hierarchically porous carbon (HPC) is prepared with the assistance of freeze-drying using colloid silica and phytic acid dipotassium salt as a hard template and phosphorus source, respectively. Intensive material characterizations show that the freeze-drying process can effectively promote the porosity of HPC. The specific surface area and P content for HPC can reach up to $892 \mathrm{~m}^{2} \mathrm{~g}^{-1}$ and 2.78 at\%, respectively. Electrochemical measurements in aqueous $\mathrm{KOH}$ and $\mathrm{H}_{2} \mathrm{SO}_{4}$ electrolytes reveal that $\mathrm{K}^{+}$of a smaller size can more easily penetrate the inner pores compared with $\mathrm{SO}_{4}{ }^{2-}$, while the developed microporosity in HPC is conducive to the penetration of $\mathrm{SO}_{4}{ }^{2-}$. Moreover, P-doping leads to a high operation potential of $1.5 \mathrm{~V}$ for an HPC-based symmetric supercapacitor, resulting in an enhanced energy density of $16.4 \mathrm{Wh} \mathrm{kg}^{-1}$. Our work provides a feasible strategy to prepare P-doped HPC with a low dosage of phosphorus source and a guide to construct a pore structure suitable for aqueous $\mathrm{H}_{2} \mathrm{SO}_{4}$ electrolyte.
\end{abstract}

Keywords: hierarchically porous carbon; energy density; supercapacitor; current density; freezedrying

\section{Introduction}

As a new type of energy storage device, supercapacitors have attracted more and more attention in recent years. The durability of supercapacitors can be assessed by estimating their capacitance, equivalent series resistance, and impedance [1]. Among the components for supercapacitors, electrode materials and electrolytes play dominant roles in their capacitive performance [2-5]. Carbon materials with hierarchically porous structures are intensively studied due to their rational pore structures, good electric conductivity, and stability, which are beneficial when equipping carbon electrodes with different electrolytes. For instance, organic or ionic liquid electrolytes usually possess a high operation potential, which is decisive to the high energy density according to the following calculation formula for energy density: $E=0.5 C V^{2}$, where $E, C$ and $V$ stands for energy density, specific capacitance, and operation potential for the assembled supercapacitor, respectively. However, the high viscosity and low ionic conductivity for organic or ionic liquid electrolytes often restrict the output power density of supercapacitors. By contrast, aqueous electrolytes with low viscosity and good ionic conductivity usually exhibit a high-power output [6]. As a typical aqueous electrolyte, neutral electrolytes with low concentration of $\mathrm{H}^{+}$or $\mathrm{OH}^{-}$ions can endure a wide operation potential over $1.5 \mathrm{~V}$ compared with acidic or alkaline electrolytes [7-9]. Recent studies on "water-in-salt" electrolytes, in which the salt concentration exceeds the water molecules both in weight and volume, have been 
explored to achieve an operation potential range of 2.2 3 V [10-13]. Such a high operation potential can be attributed to the generated electrode-electrolyte interphase between the high-concentration salt layer and carbon surface to lock down free water molecules with large anions, suppressing the chemical activity of water electrolysis [14,15].

Although acidic and alkaline electrolytes such as $\mathrm{H}_{2} \mathrm{SO}_{4}$ and $\mathrm{KOH}$ possess a higher conductivity than neutral electrolytes, the high concentration of $\mathrm{H}^{+}$or $\mathrm{OH}^{-}$ions is conducive to the hydrogen evolution or oxygen evolution reactions during electrochemical measurements, resulting in an operation potential within the theoretical decomposition potential of 1.23 V. Many strategies have been developed to expand the operation potential window. For instance, the conjunction of alkali and acid electrolytes via a $\mathrm{K}^{+}$-conducting Nafion membrane or Janus membrane can combine the low $\mathrm{H}_{2}$ evolution potential for the negative electrode and high $\mathrm{O}_{2}$ evolution potential for the positive electrode, realizing a high stable working potential of over $2 \mathrm{~V}[16,17]$. Moreover, the operation potential window for aqueous electrolytes can be expanded by tuning the surface properties for carbon electrode materials. For instance, the introduction of oxygen or sodium functionalities on carbon cloth results in an expanded operation potential window for aqueous $\mathrm{Na}_{2} \mathrm{SO}_{4}$ electrolytes. The adsorbed $\mathrm{Na}^{+}$on the carbon surface or Na-containing group can increase the onset overpotential for an oxygen evolution reaction or inhibit the adsorption of $\mathrm{H}^{+}$in the electrolyte, thus widening the operation potential window $[18,19]$. When introducing $\mathrm{N}, \mathrm{O}, \mathrm{P}$ on porous carbon, the potential window of symmetric supercapacitor can be expanded to 1.5 and $1.9 \mathrm{~V}$ in aqueous $\mathrm{KOH}$ and $\mathrm{Na}_{2} \mathrm{SO}_{4}$ electrolyte, respectively [20]. It is widely accepted that $\mathrm{N}, \mathrm{O}$ functionalities can bring about significant pseudocapacitance by reacting with acidic electrolytes. Therefore, developing heteroatom-doped porous carbon with a high operation potential in acidic electrolytes is of great importance. Ever since Hulicova-Jurcakova and coworkers found that the introduction of phosphorus in porous carbon can promote the operation potential for $\mathrm{H}_{2} \mathrm{SO}_{4}$ electrolyte due to the blockage of active oxidation sites on porous carbon by phosphate functionalities in 2009 [21], P-doped carbons have been prepared through a phosphoric acid-activation process and used as electrode materials to widen the operation potential for $\mathrm{H}_{2} \mathrm{SO}_{4}$ electrolyte [22-24]. Recently, theoretical modeling of P-enriched multi-heteroatom doped carbon electrodes shows that heteroatom doping can decrease the adsorption energy of carbon, thus storing extra cations per site and boosting the charge storage efficiently. Furthermore, the pre-adsorbed cations on heteroatom-doped carbon can significantly impede the hydrogen evolution reaction, giving rise to a wider operation potential window [25].

Even though the phosphoric-acid activation method can simultaneously introduce phosphorus functionalities during the activation process, the prepared porous carbons usually exhibit a microporous nature. Efforts on the preparation of P-doped carbon materials with hierarchically porous structures, which has been demonstrated to be effective for supercapacitors, should also be made. Herein, we prepare a phosphorus-doped hierarchically porous carbon (HPC) through a hard-templated method using colloid silica as the template with the assistance of the freeze-drying process. Material characterizations show that the prepared porous carbon exhibits a hierarchically porous structure with micro-, meso- and macro-pores and the Brunauer-Emmett-Teller (BET) specific surface area can reach up to $892 \mathrm{~m}^{2} \mathrm{~g}^{-1} . \mathrm{CO}_{2}$ sorption analysis shows that numerous ultramicopores $(<0.6 \mathrm{~nm})$ are present in HPC. Phosphorus prefers to be doped under a high temperature $\left(800^{\circ} \mathrm{C}\right)$. Electrochemical measurements in aqueous $\mathrm{KOH}$ and $\mathrm{H}_{2} \mathrm{SO}_{4}$ electrolytes reveal that HPCs with similar BET surface areas show quite different supercapacitive properties due to the different ionic sizes of $\mathrm{K}^{+}$and $\mathrm{SO}_{4}{ }^{2-}$. Considering the detailed pore-structure parameters and ionic size in aqueous electrolyte, the developed microporosity in HPC8 is conducive to the penetration of $\mathrm{SO}_{4}{ }^{2-}$ compared with HPC6. Configurated with the P-doping and developed microporosity, the assembled symmetric supercapacitor can endure a high operation potential of $1.5 \mathrm{~V}$ and deliver a high energy density of $16.4 \mathrm{Wh} \mathrm{kg}^{-1}$ in aqueous $\mathrm{H}_{2} \mathrm{SO}_{4}$ electrolyte. 


\section{Experimental Section}

\subsection{Material Preparation}

Dopamine (hydrochloride), colloid silica (30 wt\% suspension in water), phytic acid dipotassium salt, and hydrofluoric acid (HF) were purchased from Sigma Aldrich and used as received without further purification. In a typical experiment, $0.36 \mathrm{~g}$ dopamine and $0.09 \mathrm{~g}$ phytic acid dipotassium salt were dissolved in $18 \mathrm{~mL}$ water by magnetic stirring to form a transparent solution, and then $2 \mathrm{~mL}$ colloid silica was added into the solution. The mixture was magnetically stirred for $10 \mathrm{~min}$ followed by being transferred into a plastic beaker and then immersed in liquid nitrogen and kept for another $10 \mathrm{~min}$. The frozen mixture was then placed in a freeze-dryer and dried for $24 \mathrm{~h}$. The dried product was further placed in a tube furnace and carbonized at a target temperature $\left(600\right.$ and $\left.800{ }^{\circ} \mathrm{C}\right)$ for $1 \mathrm{~h}$ with a heating rate of $2{ }^{\circ} \mathrm{C} \mathrm{min}-1$ under Ar flow rate of $50 \mathrm{~cm}^{3} \mathrm{~min}^{-1}$. The product was thoroughly washed with $\mathrm{HF}$, deionized water, and ethanol to remove the silica and dried in a vacuum oven at $100{ }^{\circ} \mathrm{C}$. The obtained porous carbons carbonized at 600 and $800{ }^{\circ} \mathrm{C}$ were labeled as HPC 6 and HPC 8 , respectively. To investigate the effect of freeze-drying on the porous structure of carbon, the mentioned mixture was directly vacuum-dried at $50{ }^{\circ} \mathrm{C}$ instead of being frozen and freeze-dried, followed by carbonized at $800{ }^{\circ} \mathrm{C}$. After the same post-treatment process, the obtained carbon sample was denoted as $\mathrm{C} 8$.

\subsection{Material Characterization}

The microstructure of the samples was characterized by X-ray diffraction (Rigaku SmartLab, Tokyo, Japan) using Cu Ka radiation and Raman spectroscopy (Wi-Tec micro Raman, Ulm, Germany) using a $532 \mathrm{~nm}$ wavelength laser. The morphologies of the samples were observed using a scanning electron microscope (SEM, FEI Verios 460, Hillsboro, OR, USA) equipped with an energy dispersive spectroscopy (EDS) detector and a transmission electron microscope (TEM, JEOL2100, Tokyo, Japan). The surface properties of the samples were characterized by X-ray photoelectron spectroscopy (XPS, K-Alpha, Thermo Fisher, Waltham, MA, USA). Physisorption analyses were performed with an ASAP 2020M analyzer (Micromeritics, Norcross, GA, USA) using nitrogen and carbon dioxide as adsorbates under 77 and $273 \mathrm{~K}$, respectively. Pore size distribution was determined by QSDFT and NLDFT methods.

\subsection{Electrochemical Measurements}

The prepared HPCs were mixed with polytetrafluoroethylene in a mass ratio of 95:5 followed by pressed onto titanium mesh to obtain the working electrode. The active material in each electrode is about $2 \mathrm{mg}$. The employed electrolytes are $1 \mathrm{M} \mathrm{H}_{2} \mathrm{SO}_{4}$ and $6 \mathrm{M}$ $\mathrm{KOH}$ aqueous solutions. All the electrochemical measurements such as cyclic voltammetry $(\mathrm{CV})$, galvanostatic charge-discharge (GCD) and electrochemical impedance spectroscopy (EIS) were conducted on an IVIUM potentiostat (Ivium-n-Stat, Eindhoven, Netherlands). In a three-electrode system, Pt foil and saturated calomel electrode (SCE) were used as counter electrode and reference electrode, respectively. The potential window was set to be $0 \sim 1$ and $-1 \sim 0 \mathrm{~V}$ for acidic and alkaline electrolytes, respectively. The gravimetric specific capacitance $\left(\mathrm{C}_{\mathrm{g}}, \mathrm{F} \mathrm{g}^{-1}\right)$ is calculated from the discharge curves according to the following equation: $C_{g}=I \Delta t / m V$, where $I, \Delta t, m$ and $V$ are the discharge current, discharge time, mass of active material in each electrode and potential window, respectively. Symmetric supercapacitor cells with $\mathrm{H}_{2} \mathrm{SO}_{4}$ electrolyte were also assembled with two working electrodes. The operation potential was set to be 1 and $1.5 \mathrm{~V}$ for HPC8. Energy density $(E$, Wh kg $\left.{ }^{-1}\right)$ and power density $\left(P, \mathrm{~kW} \mathrm{~kg}^{-1}\right)$ of the cells could be calculated according to the equations: $C_{\text {cell }}=I \Delta t / 2 m V, E=C_{\text {cell }} V^{2} / 7.2, P=E / \Delta t$, where $C_{\text {cell }}$ is the specific capacitance for the supercapacitor.

\section{Results and Discussion}

Colloid silica was used as a hard template to prepare hierarchically porous carbon. As shown in Scheme 1, the carbon precursor and phosphorus source were dissolved in 
colloid silica under magnetic stirring for $10 \mathrm{~min}$. The obtained dispersion was frozen by liquid nitrogen followed by freeze-drying and further pyrolysis at target temperatures under Ar protection. The carbonized product was washed with HF acid to remove the silica template, obtaining the final HPC.

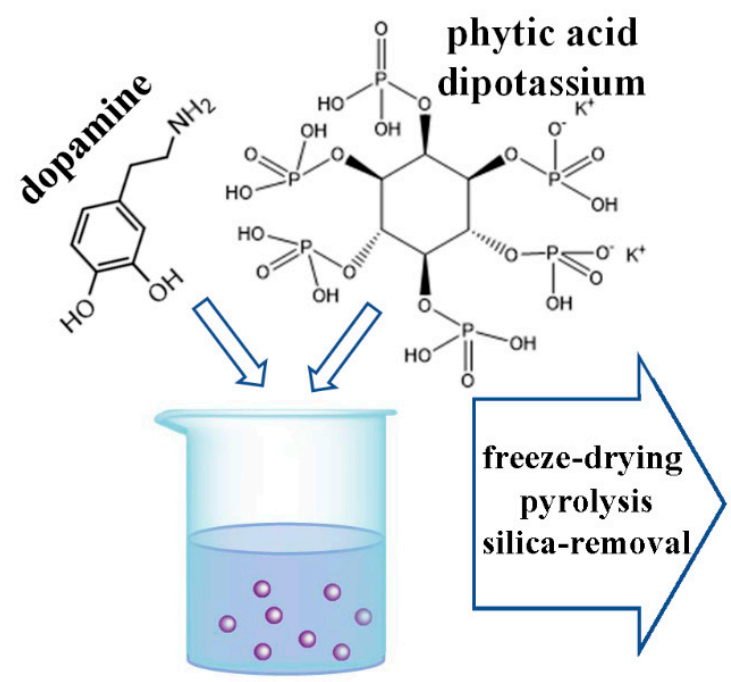

colloid silica

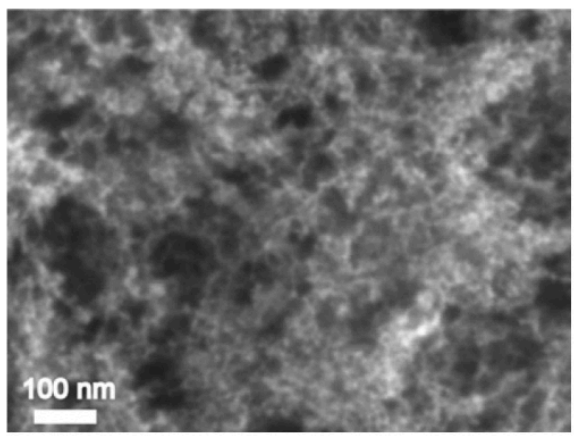

P-doped HPC

Scheme 1. Schematic preparation of HPC.

The prepared HPCs possess a sheet-like structure with a size of several tens of microns (Figures 1a and S1a). Uniform macropores with the size of several tens of nanometers to $300 \mathrm{~nm}$ can be observed on the surface of the sheet-like structure (Figure 1b,c)—compared with the SEM images for C8 (Figure S2) in which a flat surface with only a few macropores can be found. It can be inferred that the macropores in HPCs are generated due to the freeze-drying procedure. The water solvent was immediately frozen to solid ice during the liquid nitrogen freezing process. Furthermore, the freeze-drying process drives the sublimation of ice by leaving abundant macropores on the final carbon product. Apart from macropores, numerous mesopores with sizes of $\sim 20 \mathrm{~nm}$ can be observed on TEM images (Figure 1d-g). These uniformly distributed mesopores are most probably derived from a silica template. Moreover, the relatively long-range parallel stacking of curved carbon layers could be observed as shown by arrows on the HR-TEM images (Figure 1e,g), indicating a relatively good crystallization for HPCs. Meanwhile, curved carbon layers (as marked in Figure 1e,g) give rise to nanoporosity, and serve as an active site for energy storage during electrochemical measurements. Elemental mappings for HPC8 show that apart from carbon elements, phosphorus, oxygen and nitrogen elements are uniformly distributed in this carbon sample (Figures $1 \mathrm{~h}, \mathrm{k}$ and S3). The successive phosphorus doping was fulfilled, although very little phytic acid dipotassium was introduced as a phosphorus precursor. XPS analysis, to be discussed later, further confirms that there is a successive doping of phosphorus. Additionally, it shows an increase in $\mathrm{P}$ content as the carbonization temperature increases from 600 to $800{ }^{\circ} \mathrm{C}$ and the $\mathrm{P}$ content is detected to be 2.78 at $\%$ for HPC8 (Table 1). 


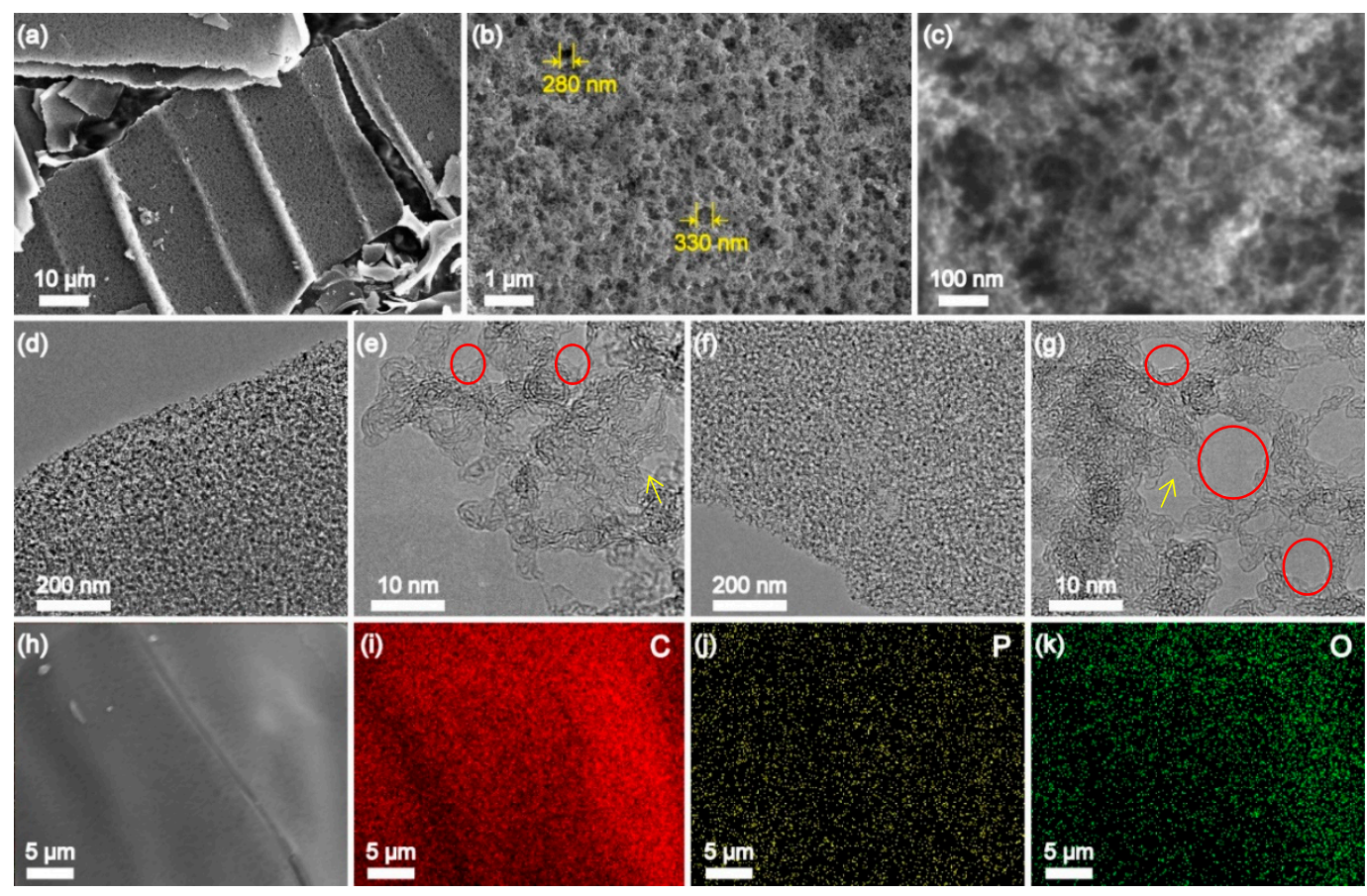

Figure 1. SEM images of HPC8 (a-c), TEM images for HPC8 (d,e) and HPC6 (f, $\mathbf{g})$ and EDS element mapping for HPC8 (h-k).

Table 1. Atomic percentage (at \%) for each element in HPCs detected by EDS and XPS.

\begin{tabular}{ccccccccc}
\hline Sample & $\mathbf{C}^{\mathbf{a}}$ & $\mathbf{O}^{\mathbf{a}}$ & $\mathbf{N}^{\mathbf{a}}$ & $\mathbf{P}^{\mathbf{a}}$ & $\mathbf{C}^{\mathbf{b}}$ & $\mathbf{O}^{\mathbf{b}}$ & $\mathbf{N}^{\mathbf{b}}$ & $\mathbf{P}^{\mathbf{b}}$ \\
\hline HPC6 & 90.25 & 4.23 & 5.19 & 0.33 & 91.01 & 5.97 & 2.45 & 0.58 \\
HPC8 & 87.11 & 5.56 & 4.55 & 2.78 & 87.88 & 8.67 & 0.96 & 2.49 \\
\hline
\end{tabular}

a detected by EDS; ${ }^{\mathrm{b}}$ detected by XPS.

Gas sorption analyses were employed to further detect the surface area and porestructure parameters for HPCs. The adsorbed quantities (Figure 2a) of $\mathrm{N}_{2}$ for both samples can reach a plateau in the low relative pressure region $\left(\mathrm{P} / \mathrm{P}_{0}<0.01\right)$, which suggests the existence of micropores and small mesopores. Obvious hysteresis loops suggest the presence of mesopores in HPCs. The higher adsorbed quantity in the high relative pressure region $\left(0.9<\mathrm{P} / \mathrm{P}_{0}<1.0\right)$ for HPC 8 than that for HPC6 reveals a more developed porous structure for HPC8. In comparison, a relatively lower adsorbed quantity within the whole relative pressure region for C8 (Figure S4) suggests the lower content for micropores and mesopores. $\mathrm{CO}_{2}$ sorption analysis under a relatively high temperature $(273 \mathrm{~K})$ was used to probe the microporosity of HPCs. The adsorbed quantity (inset in Figure 2a) for HPC8 is also higher than that of HPC6 within the whole relative pressure region, indicating a more developed microporosity for HPC8.

The corresponding pore size distributions derived from $\mathrm{N}_{2}$ and $\mathrm{CO}_{2}$ sorption branches provide a better visualization of the porous structure (Figure $2 b$ ). The QSDFT pore size distribution shows typical micropore $(\sim 0.72 \mathrm{~nm})$ and mesopore $(15-30 \mathrm{~nm})$ distribution and the latter one is inherited from silica template. The size of the mesopores coincides well with the TEM observations. Compared with HPC6, the increased peak intensities of the peaks centered at $<1 \mathrm{~nm}$ and $20-30 \mathrm{~nm}$ for HPC 8 reveal that high-temperature carbonization leads to the increase in these pores, contributing to the enlargement of pore volume. The specific surface areas and pore volumes for HPC 8 and C8 (Table 2) confirm that the freeze-drying process can significantly promote the porosity of the carbon product. The NLDFT pore size distribution derived from $\mathrm{CO}_{2}$ sorption shows that numerous ultramicropores smaller than $0.6 \mathrm{~nm}$ can be detected by the $\mathrm{CO}_{2}$ probe. Moreover, it is obvious that HPC 8 shows a higher content of ultramicropores than that of HPC6. The tabulated surface area and 
pore-structure parameters for HPCs (Table 2) suggest that even though HPCs have close BET specific surface areas, the micropore surface area determined by the $\mathrm{CO}_{2}$ probe for HPC8 is much larger than that of HPC6.
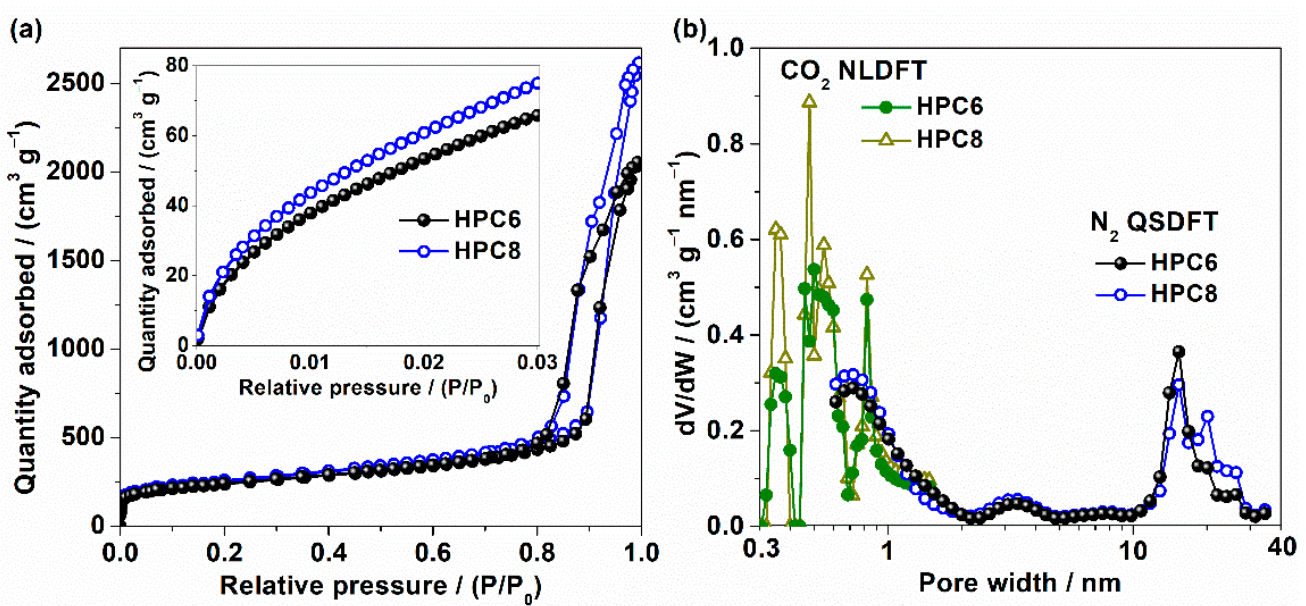

Figure 2. Nitrogen sorption isotherms (a), carbon dioxide sorption isotherms (inset in a) and their corresponding pore size distributions (b) for HPC6 and HPC8.

Table 2. Surface area and pore-structure parameters for HPCs.

\begin{tabular}{|c|c|c|c|c|c|c|c|c|}
\hline \multirow{2}{*}{ Sample } & $V_{t}{ }^{a}$ & $S_{\text {BET }}^{b}$ & S $_{\text {QSDFT }}{ }^{c}$ & $S_{\text {mic }}{ }^{c}$ & $S_{\text {meso }}^{c}$ & $S_{\text {NLDFT }}{ }^{d}$ & $S_{<0.6 \mathrm{~nm}}{ }^{\mathrm{d}}$ & $S_{0.6-1.5 \mathrm{~nm}}{ }^{\mathrm{d}}$ \\
\hline & $\left(\mathrm{cm}^{3} \mathrm{~g}^{-1}\right)$ & \multicolumn{7}{|c|}{$\left(m^{2} g^{-1}\right)$} \\
\hline HPC6 & 3.18 & 843 & 828 & 480 & 348 & 691 & 437 & 254 \\
\hline HPC8 & 4.05 & 892 & 904 & 518 & 386 & 787 & 492 & 295 \\
\hline C8 & 2.18 & 458 & 445 & 227 & 218 & - & - & - \\
\hline
\end{tabular}

${ }^{a}$ total pore volume measured at $\mathrm{P} / \mathrm{P}_{0}=0.995,{ }^{\mathrm{b}}$ BET specific surface area, ${ }^{\mathrm{c}}$ total surface area $\left(\mathrm{S}_{\mathrm{QSDFT}}\right)$, surface area for micropore ( $\left.\mathrm{S}_{\text {mic }}\right)$ and mesopore $\left(\mathrm{S}_{\text {meso }}\right)$ derived from $\mathrm{N}_{2}$ QSDFT calculation, ${ }^{\mathrm{d}}$ micropore surface area $\left(\mathrm{S}_{\mathrm{NLDFT}}\right)$, surface area for pore size $<0.6 \mathrm{~nm}\left(\mathrm{~S}_{<0.6 \mathrm{~nm}}\right)$ and $0.6-1.5 \mathrm{~nm}\left(\mathrm{~S}_{0.6-1.5 \mathrm{~nm}}\right)$ derived from $\mathrm{CO}_{2} \mathrm{NLDFT}$ calculation.

The XRD patterns of HPCs (Figure 3a) exhibit a distinct peak centered at $2 \theta=21.2^{\circ}$, suggesting a relatively good graphitization degree for HPCs. Such a result can coincide well with the HR-TEM observation (Figure 1e,g). The calculated $\mathrm{d}_{002}$ for HPCs is about $0.418 \mathrm{~nm}$. The higher d002 value compared with that of graphite is probably due to the heteroatom doping, which expands the interlayer distance between adjacent carbon layers. Two distinct peaks in the Raman spectra for HPCs (Figure 3b) at 1351 and $1589 \mathrm{~cm}^{-1}$ are assigned to the $\mathrm{D}$ and $\mathrm{G}$ bands for carbon materials, respectively. The $\mathrm{D}$ band is assigned to the disorder-induced mode associated with structural defects and imperfections while the $\mathrm{G}$ band is assigned to the first-order scattering of the E2g mode from the $\mathrm{sp}^{2}$ carbon domains [26]. The intensity ratio $\mathrm{I}_{\mathrm{G}} / \mathrm{I}_{\mathrm{D}}$ is used as a measure of the graphitization degree for carbon samples. Both HPCs possess an $\mathrm{I}_{\mathrm{G}} / \mathrm{I}_{\mathrm{D}}$ value higher than 1, 1.11 for HPC6 and 1.09 for HPC8, indicating a good graphitization degree for HPCs. The XPS analyses show that phosphorus and nitrogen are doped in HPCs (Figure 3c). The N 1s spectrum could be deconvolved into three peaks at $398.1,400.5$ and $403.3 \mathrm{eV}$, which could be assigned to pyridinic (N1), pyrrolic (N2) and pyridine-N-oxide (N3) nitrogen species, respectively [27]. The P 2p spectrum could be deconvolved into three peaks at 131.2, 132.8 and $134.3 \mathrm{eV}$, corresponding to $\mathrm{P}-\mathrm{C}$ bonding $(\mathrm{P} 1)$, pyrophosphate $\left(\left[\mathrm{P}_{2} \mathrm{O}_{7}\right]^{4-}, \mathrm{P} 2\right)$ and metaphosphate $\left(\left[\mathrm{PO}_{3}\right]^{-}, \mathrm{P} 3\right)$ species, respectively [22]. The contents of $\mathrm{N}$ and $\mathrm{P}$ (Table 1 ) in HPCs suggests that nitrogen would escape under a high-temperature treatment while P prefers to stay under a high temperature. 

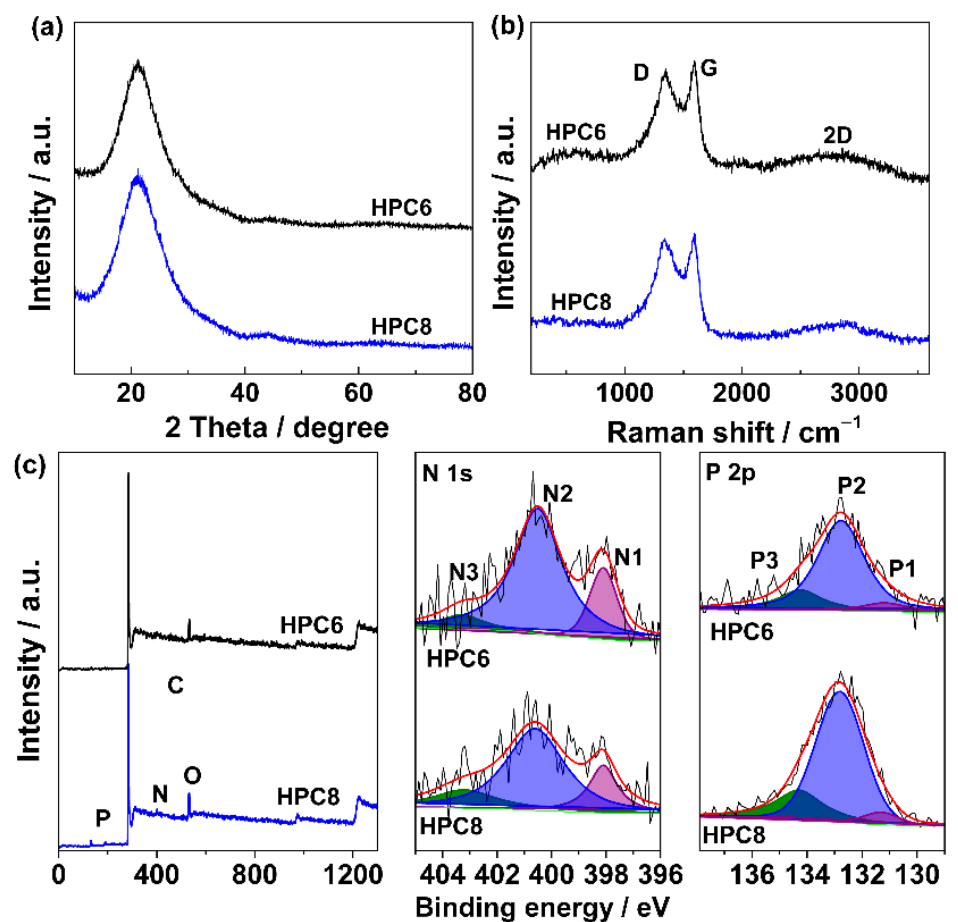

Figure 3. (a) XRD patterns, (b) Raman spectra, (c) XPS convey, N 1s and P 2p spectra for HPCs.

Electrochemical measurements were systematically employed in $1 \mathrm{M} \mathrm{H}_{2} \mathrm{SO}_{4}$ and $6 \mathrm{M}$ $\mathrm{KOH}$ electrolytes in a three-electrode system. It is shown that HPC8 exhibits a much higher response current density than that of HPC6 during CV measurements in both electrolytes (Figures 4a, S6a and S7a). Additionally, obvious redox peaks could be found in the CV curves for HPC8, suggesting the presence of pseudocapacitance, which is attributed to the faradic reactions between surface functionalities and electrolytes. The deviation from a linear shape for the GCD curves (Figures $4 b, S 6 b$ and S7b) further confirms the presence of pseudocapacitance. The current density dependence of specific capacitance (Figures $4 \mathrm{c}$ and S6c) shows that HPC8 possesses a much higher specific capacitance than that of HPC6 regardless of whether in a $\mathrm{KOH}$ or $\mathrm{H}_{2} \mathrm{SO}_{4}$ electrolyte. The corresponding areal capacitance for HPC8 is much larger than that of HPC6 in both electrolytes (Table 3), suggesting an improved usage efficiency for the available surface area to electrolyte. Additionally, HPCs show higher areal capacitance in $\mathrm{H}_{2} \mathrm{SO}_{4}$ electrolyte than that in $\mathrm{KOH}$ electrolyte, which is because the surface oxygen/nitrogen functionalities prefer to introduce pseudocapacitance in acidic electrolyte. However, each HPC sample exhibits a higher capacitance retention ratio (Figure S8) in $\mathrm{KOH}$ electrolyte than that in $\mathrm{H}_{2} \mathrm{SO}_{4}$ electrolyte. Such a trend can be attributed to the difference in ionic size and porous structure for HPCs. $\mathrm{K}^{+}$and $\mathrm{SO}_{4}{ }^{2-}$ are preferentially adsorbed on the electrode/electrolyte interface in the negative and positive potential ranges in $\mathrm{KOH}$ and $\mathrm{H}_{2} \mathrm{SO}_{4}$ electrolyte, respectively. Additionally, $\mathrm{K}^{+}$possesses a smaller ionic size $(0.36-0.42 \mathrm{~nm})$ than that of $\mathrm{SO}_{4}{ }^{2-}(>0.58 \mathrm{~nm})$ [28]. Our previous study reveals that ultramicropores are able to be penetrated by $\mathrm{K}^{+}[29,30]$. Therefore, the high capacitance retention ratio in $\mathrm{KOH}$ electrolyte for each $\mathrm{HPC}$ is because it is easier for $\mathrm{K}^{+}$to penetrate the inner pores. As discussed above, HPC 8 shows an obviously higher micropore volume with the pore size $<1 \mathrm{~nm}$. In this case, an enhanced supercapacitive performance in $\mathrm{H}_{2} \mathrm{SO}_{4}$ electrolyte for HPC8 is achieved in comparison with HPC6. 

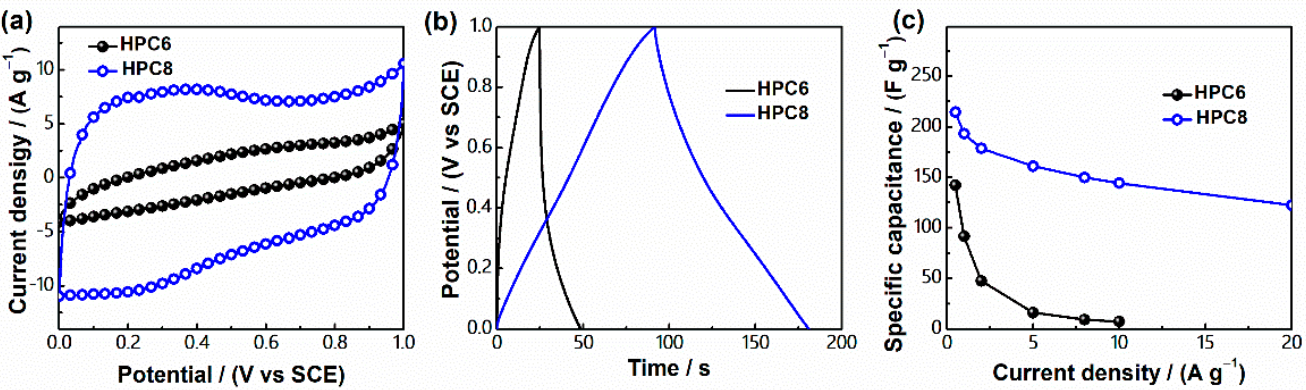

Figure 4. Supercapacitive performance for $\mathrm{HPCs}$ in $1 \mathrm{M} \mathrm{H}_{2} \mathrm{SO}_{4}$ with a three-electrode configuration: (a) CV curves at a scan rate of $50 \mathrm{mV} \mathrm{s}^{-1}$, (b) GCD curve at a current density of $2 \mathrm{~A} \mathrm{~g}^{-1}$, (c) specific capacitances at different current densities.

Table 3. Gravimetric and areal capacitances for HPCs in different electrolytes.

\begin{tabular}{|c|c|c|c|c|}
\hline \multirow{2}{*}{ Sample } & \multicolumn{2}{|c|}{$\mathrm{H}_{2} \mathrm{SO}_{4}$} & \multicolumn{2}{|c|}{$\mathrm{KOH}$} \\
\hline & $C_{g}\left(F g^{-1}\right)^{a}$ & $C_{s}\left(\mu \mathrm{F} \mathrm{cm}^{-2}\right)^{b}$ & $C_{g}\left(F g^{-1}\right)^{a}$ & $C_{s}\left(\mu \mathrm{F} \mathrm{cm}^{-2}\right)^{b}$ \\
\hline HPC6 & 142 & 17 & 132 & 16 \\
\hline HPC8 & 215 & 24 & 181 & 20 \\
\hline
\end{tabular}

a gravimetric capacitance calculated at the current density of $0.5 \mathrm{~A} \mathrm{~g}^{-1}, \mathrm{~b}$ areal capacitance by dividing gravimetric capacitance at the current density of $0.5 \mathrm{~A} \mathrm{~g}^{-1}$ with BET specific capacitance.

To investigate the chemical and physical processes on the interface of electrode and electrolyte, electrochemical impedance spectroscopy was carried out and the corresponding Nyquist plot is shown in Figure 5a. The intercept with the real axis of the plot indicates the equivalent series resistance (ESR) value, which is known as the internal resistance, defined as the sum of the resistances of the electrode, electrolyte and the contact resistance between the electrode and current collector. Considering that the same current collector and electrolyte are used in this work, the ESRs could be a reference for the intrinsic resistance of carbon materials. The ESRs for HPCs were found to be 0.51 (HPC8) and $0.60 \Omega$ (HPC6), revealing a good electrical conductivity for both samples. At the medium-high frequency region, the diameter of the semicircle represents the charge transfer resistance $\left(R_{\mathrm{ct}}\right)$, which is correlated with the porous nature of carbon in accordance with electrolyte-accessible area and electrical conductivity. The absence of a semicircle for HPC6 reveals that electron transfer probably occurs within the large fraction of wide pores (mesopores) that have easy accessibility and minimal charge [31]. Such a result further confirms that electrolytes cannot penetrate the inner pores of HPC6, resulting in a low surface usage efficiency for HPC6. The equivalent circuit and fitted resistances for HPC8 can be found in Supporting Information (Figure S9 and Table S1). At the low frequency region, the slope for HPC8 is close to $90^{\circ}$ along the - $Z^{\prime \prime}$, suggesting an EDL-dominated capacitive nature. The deviation from the straight line along the -Z" for HPC6 indicates a nonideally polarizable electrode. Figure $5 \mathrm{~b}$ shows the dependence of capacitance on the frequency for HPCs. The capacitance gradually decreases with the increase in frequency, suggesting that the electrolyte ions are unable to penetrate the surface of electrode at high frequency. The capacitance values for HPC8 at low frequency $(0.01 \mathrm{~Hz})$ are much higher than that of HPC6, which coincides well with the result of GCD at the current density of $1 \mathrm{~A} \mathrm{~g}^{-1}$. In comparison with the capacitance variation trend of HPC8, the capacitances for HPC6 do not show signs of saturation at the low frequency of $0.01 \mathrm{~Hz}$, suggesting that equilibrium ion adsorption is not achieved within $100 \mathrm{~s}$. The relationship between phase angle and frequency (Figure 5c) shows that the phase angle for $\mathrm{HPC} 8$ is $-82^{\circ}$, while the value for $\mathrm{HPC} 6$ is $-50^{\circ}$, suggesting a better EDL-dominated capacitive nature for HPC8. It is shown that the frequency-dependent impedance decreases with the increase in frequency for all samples (Figure $5 \mathrm{~d}$ ). Typically, HPC8 possesses a lower impedance compared with HPC6, which is beneficial for ionic 
diffusion from the electrolyte to porous electrode, resulting in a good supercapacitive performance for HPC8.
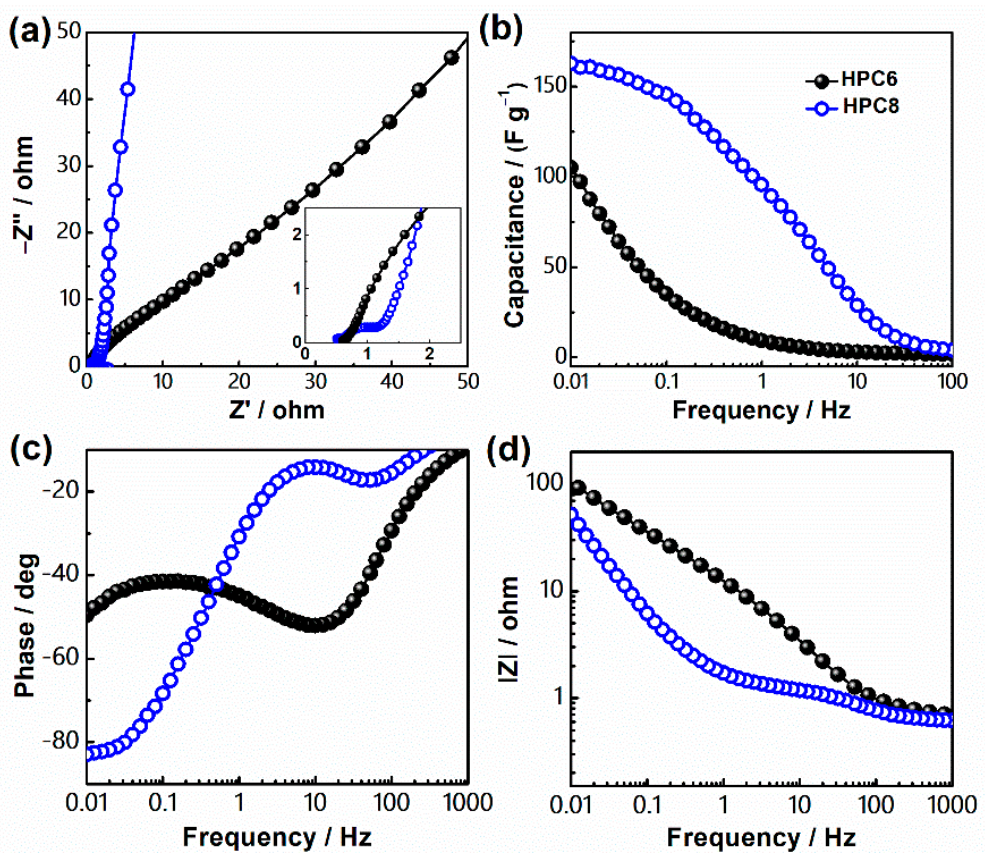

Figure 5. (a) Nyquist plot, frequency dependence of (b) capacitance, (c) phase angle and (d) $|\mathrm{Z}|$ for HPCs in $\mathrm{H}_{2} \mathrm{SO}_{4}$ electrolyte.

As for P-doped carbons, it was reported that the active oxidation sites on the surface of porous carbon can be blocked by phosphate functionalities, resulting in an operation potential higher than $1.5 \mathrm{~V}$. Considering that $\mathrm{HPC} 8$ with a relatively high $\mathrm{P}$ content shows a perfect supercapacitive performance in $\mathrm{H}_{2} \mathrm{SO}_{4}$ electrolyte, an $\mathrm{HPC} 8$-based symmetric supercapacitor was assembled and tested under the operation potentials of 1 and $1.5 \mathrm{~V}$ in $1 \mathrm{M}$ aqueous $\mathrm{H}_{2} \mathrm{SO}_{4}$ electrolyte. The Nyquist plot for the HPC8-based symmetric supercapacitor (Figure S10) shows a low internal resistance of $1 \Omega$. CV curves (Figure 6a) at a low operation potential show a pair of redox peaks, suggesting the energy storage mechanism of EDL capacitance and pseudocapacitance, which is generated by the redox reaction between $\mathrm{H}^{+}$and surface functionalities [32]. However, the absence of redox peaks for $\mathrm{CV}$ curves (Figures $6 \mathrm{a}$ and S11a) measured under a $1.5 \mathrm{~V}$ operation potential window suggests that the EDL capacitance dominated the energy storage mechanism under such a high operation potential window. The overlapped GCD curves (Figures $6 \mathrm{~b}$ and $\mathrm{S11b}$ ) measured at different operation potentials reveal a good reversibility for HPC8. The energy density for the $1.5 \mathrm{~V}$ supercapacitor can reach up to $16.4 \mathrm{Wh} \mathrm{kg}^{-1}$, which is much larger than that $\left(6 \mathrm{Wh} \mathrm{kg}^{-1}\right)$ of the $1 \mathrm{~V}$ supercapacitor. Moreover, with the hierarchically porous structure, the energy density can be retained at $9 \mathrm{Wh} \mathrm{kg}^{-1}$, even at a high power output of $7500 \mathrm{~W} \mathrm{~kg}^{-1}$. The cyclic stability and CV curves at different cycles for the HPC8-based symmetric supercapacitor (Figure S12) suggest the EDL capacitance-dominated energy storage mechanism of HPC8. The inadequate durability for such carbon is probably due to its developed porous structure. 

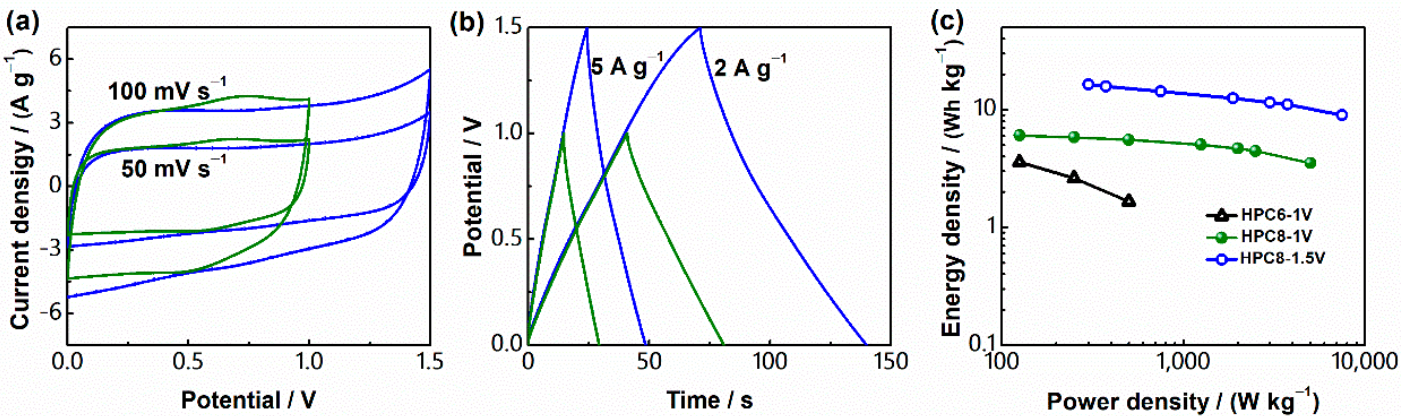

Figure 6. Supercapacitive performance for HPC-based symmetric supercapacitors with operation potential of 1 and $1.5 \mathrm{~V}$ : (a) CV curves for HPC8 at the scan rates of 50 and $100 \mathrm{mV} \mathrm{s}^{-1}$, (b) GCD curves for HPC8 at the current densities of 2 and $5 \mathrm{~A} \mathrm{~g}^{-1}$, (c) Ragone plot.

\section{Conclusions}

Hierarchically porous carbons with P-doping were prepared through a hard-templating method with the assistance of the freeze-drying process, which leads to a developed porosity for HPC. A low-dose phosphorus source (phytic acid dipotassium salt) can ensure a successive $\mathrm{P}$-doping, and $\mathrm{P}$ atoms prefer to be stably doped at a high carbonization temperature of $800{ }^{\circ} \mathrm{C}$. Electrochemical measurements in $\mathrm{KOH}$ and $\mathrm{H}_{2} \mathrm{SO}_{4}$ electrolytes reveal that $\mathrm{K}^{+}$more easily penetrates the inner pores compared with $\mathrm{SO}_{4}{ }^{2-}$ due to their ionic size difference, whereas a more developed microporosity in HPC is conducive to the penetration of $\mathrm{SO}_{4}{ }^{2-}$. Moreover, P-doping in HPC leads to a stable operation potential up to $1.5 \mathrm{~V}$ in $\mathrm{H}_{2} \mathrm{SO}_{4}$ electrolyte for the assembled symmetric supercapacitor. Our work provides a feasible strategy to prepare P-doped HPC for a supercapacitor with a high operation potential and a guide to construct a pore structure suitable for aqueous $\mathrm{H}_{2} \mathrm{SO}_{4}$ electrolyte.

Supplementary Materials: The following are available online at https://www.mdpi.com/article/10 .3390/nano11112838/s1, Figure S1: SEM images for HPC6; Figure S2: SEM images for C8; Figure S3: EDS element mapping of nitrogen for HPC8; Figure S4: Nitrogen sorption isotherm and QSDFT pore size distribution (inset) for C8; Figure S5: Cumulative surface areas derived from QSDFT method for C8 and HPCs; Figure S6: Supercapacitive performance for HPC8 in $1 \mathrm{M} \mathrm{H}_{2} \mathrm{SO}_{4}$ electrolyte with a three-electrode system: (a) CV curves at different scan rates, (b) GCD curve at different current densities; Figure S7: Supercapacitive performance for HPCs in $6 \mathrm{M} \mathrm{KOH}$ electrolyte with a three-electrode system: (a) CV curves at a scan rate of $50 \mathrm{mV} \mathrm{s}^{-1}$, (b) GCD curve at a current density of $2 \mathrm{~A} \mathrm{~g}^{-1}$, (c) specific capacitances at different current densities; Figure S8: Capacitance retention ratio for HPCs in $\mathrm{KOH}$ and $\mathrm{H}_{2} \mathrm{SO}_{4}$ electrolytes; Figure S9: The equivalent circuit for HPC8 in $\mathrm{H}_{2} \mathrm{SO}_{4}$ electrolyte; Figure S10: Nyquist plot for HPC8-based symmetric supercapacitor; Figure S11: Supercapacitive performance for HPC8-based symmetric supercapacitor: (a) CV curves at different scan rates, (b) GCD curves at different current densities; Figure S12: (a) Cyclic stability for HPC8-based symmetric supercapacitor, (b) CV curves (inset) at different cycles; Table S1. The fitted resistances for $\mathrm{HPCs}$ in $\mathrm{H}_{2} \mathrm{SO}_{4}$ electrolyte.

Author Contributions: Conceptualization, X.W. (Xiaozhong Wu) and J.Z. (Jin Zhou); methodology, X.Y. and X.W. (Xin Wang); validation and resources, Z.M., P.Z. and J.Z. (Jinping Zhao); investigation and data curation, X.Y., X.W. (Xin Wang) and W.F.; writing-original draft preparation and writingreview and editing, X.W. (Xiaozhong Wu) and J.Z. (Jin Zhou); supervision and project administration, S.Z.; funding acquisition, X.W. (Xiaozhong Wu) and S.Z. All authors have read and agreed to the published version of the manuscript.

Funding: This research was financially supported by the National Natural Science Foundation of China (NSFC 51907110, 21901146, 22078179, 21978159), Natural Science Foundation of Shandong Province (ZR2020QB048, ZR2019MB034), Taishan Scholar Foundation (tsqn201812063) and the Opening Fund of State Key Laboratory of Heavy Oil Processing (SKLOP202002004).

Institutional Review Board Statement: Not applicable. 
Informed Consent Statement: Not applicable.

Data Availability Statement: Data are contained within the article.

Conflicts of Interest: The authors declare no conflict of interest.

\section{References}

1. Szewczyk, A. Measurement of noise in supercapacitors. Metrol. Meas. Syst. 2017, 24, 645-652. [CrossRef]

2. Yang, X.Q.; Liu, A.R.; Zhao, Y.W.; Lu, H.J.; Zhang, Y.J.; Wei, W.; Li, Y.; Liu, S.Q. Three-dimensional macroporous polypyrrolederived graphene electrode prepared by the hydrogen bubble dynamic template for supercapacitors and metal-free catalysts. ACS Appl. Mater. Interfaces 2015, 7, 23731-23740. [CrossRef]

3. Li, K.L.; Feng, S.H.; Jing, C.; Chen, Y.X.; Liu, X.Y.; Zhang, Y.X.; Zhou, L. Assembling a double shell on a diatomite skeleton ternary complex with conductive polypyrrole for the enhancement of supercapacitors. Chem. Commun. 2019, 55, 13773-13776. [CrossRef]

4. Bo, X.K.; Xiang, K.; Zhang, Y.; Shen, Y.; Chen, S.Y.; Wang, Y.Z.; Xie, M.J.; Guo, X.F. Microwave-assisted conversion of biomass wastes to pseudocapacitive mesoporous carbon for high-performance supercapacitor. J. Energy Chem. 2019, 39, 1-7. [CrossRef]

5. Najib, S.; Bakan, F.; Abdullayeva, N.; Bahariqushchi, R.; Kasap, S.; Franzo, G.; Sankir, M.; Sankir, N.D.; Mirabella, S.; Erdem, E. Tailoring morphology to control defect structures in $\mathrm{ZnO}$ electrodes for high-performance supercapacitor devices. Nanoscale 2020, 12, 16162-16172. [CrossRef]

6. Beguin, F.; Presser, V.; Balducci, A.; Frackowiak, E. Carbons and electrolytes for advanced supercapacitors. Adv. Mater. 2014, 26, 2219-2251. [CrossRef]

7. Fic, K.; Lota, G.; Meller, M.; Frackowiak, E. Novel insight into neutral medium as electrolyte for high-voltage supercapacitors. Energy Environ. Sci. 2012, 5, 5842-5850. [CrossRef]

8. He, L.; Liu, Y.; Li, C.Y.; Yang, D.Z.; Wang, W.G.; Yan, W.Q.; Zhou, W.B.; Wu, Z.X.; Wang, L.L.; Huang, Q.H.; et al. A low-cost Zn-based aqueous supercapacitor with high energy density. ACS Appl. Energ. Mater. 2019, 2, 5835-5842. [CrossRef]

9. Pham, V.H.; Nguyen-Phan, T.D.; Tong, X.; Rajagopalan, B.; Chung, J.S.; Dickerson, J.H. Hydrogenated TiO ${ }_{2} @$ reduced graphene oxide sandwich-like nanosheets for high voltage supercapacitor applications. Carbon 2018, 126, 135-144. [CrossRef]

10. Dou, Q.Y.; Lei, S.L.; Wang, D.W.; Zhang, Q.N.; Xiao, D.W.; Guo, H.W.; Wang, A.P.; Yang, H.; Li, Y.L.; Shi, S.Q.; et al. Safe and high-rate supercapacitors based on an "acetonitrile/water in salt" hybrid electrolyte. Energy Environ. Sci. 2018, 11, 3212-3219. [CrossRef]

11. Xiao, D.W.; Dou, Q.Y.; Zhang, L.; Ma, Y.L.; Shi, S.Q.; Lei, S.L.; Yu, H.Y.; Yan, X.B. Optimization of organic/water hybrid electrolytes for high-rate carbon-based supercapacitor. Adv. Funct. Mater. 2019, 29, 8. [CrossRef]

12. Thareja, S.; Kumar, A. "Water-in-salt" electrolyte-based high-voltage (2.7 V) sustainable symmetric supercapacitor with superb electrochemical performance-an analysis of the role of electrolytic ions in extending the cell voltage. ACS Sustain. Chem. Eng. 2021, 9, 2338-2347. [CrossRef]

13. Tatlisu, A.; Huang, Z.F.; Chen, R.Y. High-voltage and low-temperature aqueous supercapacitor enabled by "Water-in-Imidazolium chloride" electrolytes. ChemSusChem 2018, 11, 3899-3904. [CrossRef]

14. Suo, L.M.; Borodin, O.; Gao, T.; Olguin, M.; Ho, J.; Fan, X.L.; Luo, C.; Wang, C.S.; Xu, K. “Water-in-salt” electrolyte enables high-voltage aqueous lithium-ion chemistries. Science 2015, 350, 938-943. [CrossRef]

15. Qian, X.Y.; Miao, L.; Jiang, J.X.; Ping, G.C.; Xiong, W.; Lv, Y.K.; Liu, Y.F.; Gan, L.H.; Zhua, D.Z.; Liu, M.X. Hydrangea-like N/O codoped porous carbons for high-energy supercapacitors. Chem. Eng. J. 2020, 388, 124208. [CrossRef]

16. Li, C.Y.; Wu, W.Z.; Wang, P.; Zhou, W.B.; Wang, J.; Chen, Y.H.; Fu, L.J.; Zhu, Y.S.; Wu, Y.P.; Huang, W. Fabricating an aqueous symmetric supercapacitor with a stable high working voltage of $2 \mathrm{~V}$ by using an alkaline-acidic electrolyte. Adv. Sci. 2019, 6, 1801665. [CrossRef]

17. Liang, N.; Ji, Y.S.; Xu, J.; Zuo, D.Y.; Chen, D.Z.; Zhang, H.W. An asymmetric electric double-layer capacitor with a janus membrane and two different aqueous electrolytes. J. Power Sources 2019, 423, 68-71. [CrossRef]

18. Xia, H.F.; Zhang, B.; Wang, C.H.; Cao, L.; Luo, B.; Fan, X.M.; Zhang, J.F.; Ou, X. Surface engineered carbon-cloth with broadening voltage window for boosted energy density aqueous supercapacitors. Carbon 2020, 162, 136-146. [CrossRef]

19. Qin, T.F.; Chen, H.D.; Zhang, Y.A.; Chen, X.T.; Liu, L.; Yan, D.; Ma, S.; Hou, J.; Yu, F.; Peng, S.L. Modulating surface chemistry of heteroatom-rich micropore carbon cloth electrode for aqueous $2.1 \mathrm{~V}$ high-voltage window all-carbon supercapacitor. J. Power Sources 2019, 431, 232-238. [CrossRef]

20. Deng, Y.L.; Ji, Y.J.; Wu, H.M.; Chen, F. Enhanced electrochemical performance and high voltage window for supercapacitor based on multi-heteroatom modified porous carbon materials. Chem. Commun. 2019, 55, 1486-1489. [CrossRef]

21. Hulicova-Jurcakova, D.; Puziy, A.M.; Poddubnaya, O.I.; Suarez-Garcia, F.; Tascon, J.M.D.; Lu, G.Q. Highly stable performance of supercapacitors from phosphorus-enriched carbons. J. Am. Chem. Soc. 2009, 131, 5026-5027. [CrossRef]

22. Wen, Y.Y.; Wang, B.; Huang, C.C.; Wang, L.Z.; Hulicova-Jurcakova, D. Synthesis of phosphorus-doped graphene and its wide potential window in aqueous supercapacitors. Chem. Eur. J. 2015, 21, 80-85. [CrossRef] [PubMed]

23. Huang, C.C.; Sun, T.; Hulicova-Jurcakova, D. Wide electrochemical window of supercapacitors from coffee bean-derived phosphorus-rich carbons. ChemSusChem 2013, 6, 2330-2339. [CrossRef] [PubMed]

24. Wen, Y.Y.; Rufford, T.E.; Hulicova-Jurcakova, D.; Wang, L.Z. Nitrogen and phosphorous co-doped graphene monolith for supercapacitors. ChemSusChem 2016, 9, 513-520. [CrossRef] 
25. Yu, M.H.; Lin, D.; Feng, H.B.; Zeng, Y.X.; Tong, Y.X.; Lu, X.H. Boosting the energy density of carbon-based aqueous supercapacitors by optimizing the surface charge. Angew. Chem. Int. Ed. 2017, 56, 5454-5459. [CrossRef]

26. Park, S.H.; Bak, S.M.; Kim, K.H.; Jegal, J.P.; Lee, S.I.; Lee, J.; Kim, K.B. Solid-state microwave irradiation synthesis of high quality graphene nanosheets under hydrogen containing atmosphere. J. Mater. Chem. 2011, 21, 680-686. [CrossRef]

27. Hasegawa, G.; Deguchi, T.; Kanamori, K.; Kobayashi, Y.; Kageyama, H.; Abe, T.; Nakanishi, K. High-level doping of nitrogen, phosphorus, and sulfur into activated carbon monoliths and their electrochemical capacitances. Chem. Mater. 2015, 27, 4703-4712. [CrossRef]

28. Eliad, L.; Salitra, G.; Soffer, A.; Aurbach, D. Ion sieving effects in the electrical double layer of porous carbon electrodes: Estimating effective ion size in electrolytic solutions. J. Phys. Chem. B 2001, 105, 6880-6887. [CrossRef]

29. Wu, X.Z.; Xing, W.; Florek, J.; Zhou, J.; Wang, G.Q.; Zhuo, S.P.; Xue, Q.Z.; Yan, Z.F.; Kleitz, F. On the origin of the high capacitance of carbon derived from seaweed with an apparently low surface area. J. Mater. Chem. A 2014, 2, 18998-19004. [CrossRef]

30. Wu, X.Z.; Zhou, J.; Xing, W.; Zhang, Y.; Bai, P.; Xu, B.J.; Zhuo, S.P.; Xue, Q.Z.; Yan, Z.F. Insight into high areal capacitances of low apparent surface area carbons derived from nitrogen-rich polymers. Carbon 2015, 94, 560-567. [CrossRef]

31. Saha, D.; Li, Y.C.; Bi, Z.H.; Chen, J.H.; Keum, J.K.; Hensley, D.K.; Grappe, H.A.; Meyer, H.M.; Dai, S.; Paranthaman, M.P.; et al. Studies on supercapacitor electrode material from activated lignin-derived mesoporous carbon. Langmuir 2014, 30, 900-910. [CrossRef] [PubMed]

32. Hulicova-Jurcakova, D.; Kodama, M.; Shiraishi, S.; Hatori, H.; Zhu, Z.H.; Lu, G.Q. Nitrogen-enriched nonporous carbon electrodes with extraordinary supercapacitance. Adv. Funct. Mater. 2009, 19, 1800-1809. [CrossRef] 